\title{
Characteristics of Rice Flour Breads Using Yeast Isolated from Pear Red Bartlett Fruits
}

\author{
Takeshi Nagai ${ }^{1,2,3}$, Norihisa $\mathrm{Kai}^{4}$, Yasuhiro Tanoue ${ }^{5} \&$ Nobutaka Suzuki $^{6}$ \\ ${ }^{1}$ Graduate School of Agricultural Sciences, Yamagata University, Yamagata, Japan \\ ${ }^{2}$ The United Graduate School of Agricultural Sciences, Iwate University, Iwate, Japan \\ ${ }^{3}$ Graduate School, Prince of Songkla University, Songkhla, Thailand \\ ${ }^{4}$ Graduate School of Engineering, Oita University, Oita, Japan \\ ${ }^{5}$ National Fisheries University, Yamaguchi, Japan \\ ${ }^{6}$ Nagoya Research Institute, Aichi, Japan \\ Correspondence: Takeshi Nagai, Graduate School of Agricultural Sciences, Yamagata University, Yamagata \\ 9978555, Japan. Tel: 81-235-28-2821. E-mail: nagatakenagatake@yahoo.co.jp; tnagai@tds1.tr.yamagata-u.ac.jp
}

$\begin{array}{ll}\text { Received: December 17, } 2017 & \text { Accepted: January 16, 2018 Online Published: February 15, } 2018 \\ \text { doi:10.5539/jas.v10n3p16 } & \text { URL: https://doi.org/10.5539/jas.v10n3p16 }\end{array}$

The research work was partly supported by JSPS KAKENHI Grant Number 25560032 and by a grant from the Elizabeth Arnold Fuji Foundation.

\begin{abstract}
To develop high qualities of rice flour breads, we tried to prepare breads using rice flours from major five non-glutinous rice cultivars on market shares of Japan and wild-type Saccharomyces cerevisiae strain YTPR1 isolated from pear Red Bartlett fruits. Apparent amylose contents of rice flours were measured about 12.1-19.9\%. Damaged starch contents of these flours were about $22 \%$ regardless to the kinds of rice cultivars. Gluten was added about $20 \mathrm{wt} . \%$ based on rice flour, and breads were made in the same way. Any bread has caused caving. Next, the amount of water added in dough was regulated in consideration of moisture contents of rice flours. Except for Akitakomachi flour, breads largely expanded, although loaves volumes did not amount to that on bread made from bread flour and commercially available baker's dried yeast. It was observed correlation between the amount of water and amylose contents of rice flours with $\mathrm{R}^{2}=0.703$. It suggested that the amount of water added in dough might estimate from amylose contents of rice flours. Specific volumes of these loaves were low compared with that made from bread flour. However, by sensory analysis, breads made from Hinohikari and Haenuki flours had total points closest to that made from bread flour: it could produce high quality of breads using Hinohikari and Haenuki flours and yeast isolated from pear Red Bartlett fruits.
\end{abstract}

Keywords: bread making, property, Saccharomyces cerevisiae strain YTPR1

\section{Introduction}

Rice is one of the three major cereals in the world, and world production is about 483 million tons per year (USDA, 2017). China is the largest producer (about 146 million tons), and is followed by India, Indonesia, Bangladesh, and Vietnam. Production is about 7.6 million tons in Japan. Most of rice is produced and consumed in these Asian countries. Eating habits of Japanese has been changed and westernized and demand for domestic agricultural products has decreased for cheaper imported foods. Food self-sufficiency rate based on calories in Japan has been low and it for FY2016 is lowest about 38\% among 10 developed countries such as Canada, Australia, America, and France (Ministry of Agriculture, Forestry and Fisheries, 2017a). It is required aggressive use of domestic foodstuff to improve self-sufficiency in food products. So, it is expected consumption of rice for the staple food that is almost $100 \%$ self-sufficient. However, there is a limit in consumption of it as eating rice, because consumption of it decreases about $54 \mathrm{~kg}$ per person per year for FY2016 (Ministry of Agriculture, Forestry and Fisheries, 2017b). According to the average Family income and expenditure survey in Japan for 2014-2016 based on two or more person household by the Statistics Bureau, Ministry of Internal Affairs and Communications (Ministry of Internal Affairs and Communications, 2017), expenditure for breads exceeds that 
of rice. So, it is considered that flour foods such as breads and noodles leads to high utilization of rice and expansion in consumption of rice. Breads prepared using bread flours can be classified roughly into three types as follows: partial substitution bread, gluten added bread, and gluten-free bread. Among them, it is not easy for rice to make bread because rice dose not contain gluten. On the contrary, gluten added breads is made by addition of gluten about $20 \mathrm{wt} . \%$ based on the weight of rice flours. From the purpose of expansion in consumption of rice, it is desirable to develop production methods of high qualities of gluten added breads using rice of different varieties.

Yeast for the production of fermented foods such as breads, wines, and beers belong to Saccharomycetaceae. Generally, dried yeasts (baker's yeasts strain Saccharomyces cerevisiae) are widely used in bread making because of long-term storage ability. On the other hand, wild-type yeasts possess characteristic aroma and assimilative ability associated with growth environments. Recently, development of breads using wild-type yeast is receiving a lot of attention in baking industries. For example, yeasts such as Shirakamikodama yeast (Shimosaka, 2011), Minowa yeast (Sekiguchi, 2008), and Tokachino yeast (Oda et al., 2012) were separated and isolated, and then were utilized for bread making using bread flour. Tosa et al. (2015) prepared flour from rice cultivar, Kinumusume from Shimane, Japan, and tried to make bread using Umehana yeast that was isolated from plum blossoms in Iwami-Ginzan, a world heritage site. As a result, they clarified that it was negative correlation between damaged starch content of flour and specific volume of bread; it was desirable that damaged starch contents was low for bread making using Kinumusume flour. Leavening ability on dough prepared using Kinumusume flour and Umehana yeast in condition for making white bread was higher than that using bread flour. Moreover, they elucidated the appropriate amount of water added in dough was about $77-85 \mathrm{wt} . \%$ based on the weight of rice flours by Farinograph tests. Tayama et al. (2016) isolated yeasts from fruits and flowers for production of gluten-free bread using rice flour. Among 132 strains obtained, strain LFWP30G from lemon fruits showed high level of $\mathrm{CO}_{2}$ productivity in dough using rice flour containing $3 \%$ sucrose. There were no significant differences on sensory evaluation between rice flour bread using strain LFWP30G and wheat flour bread using commercially available baker's yeast. However, rice flour bread using strain LFWP30G had a moist and soft eat-feeling in crumb in comparison with wheat flour bread using commercially available baker's yeast. Finally, they suggested that strain LFWP30G was suitable for bread made from rice flour.

Just recently, we have succeeded in isolation of $S$. cerevisiae strain with high gassing power and ethanol productivity from pear Red Bartlett fruits harvested in Yamagata, Japan, and strain YTPR1 was identified as $S$. cerevisiae by its $28 \mathrm{~S}$ rRNA sequence analysis (DDBJ/EMBL/GenBank Accession Number LC331262). We have also elucidated that high quality of bread with acceptable attributes could make from bread flour and strain YTPR1. In the present study, we tried to prepare breads using rice flours from five species of rice cultivars and strain YTPR1, and to compare properties of these breads with that of bread made from bread flour and commercially available baker's yeast to develop high qualities of rice flour breads.

\section{Materials and Methods}

\subsection{Ingredients}

Rice flours from five species of rice cultivars Akitakomachi, Koshihikari, Haenuki, Hitomebore, and Hinohikari were obtained from Akitainsatuseihon Co. (Akita, Japan), Kichijiya kokuten Co. (Yamanashi, Japan), Yoshida seihun Co. (Yamagata, Japan), Sugaya Ltd. (Iwate, Japan), and Ooshima farm (Kumamoto, Japan), respectively. Market shares of these major non-glutinous rice cultivars accounts for about $65 \%$ of total domestic proportion of planted areas of Japan in 2016 (Rice Organization, 2017). Commercially available bread flour from wheat and salt were purchased from Kobe Bussan Co., Ltd. (Hyogo, Japan). Commercially available baker's dried yeast (Supercamellia) was obtained from Nissin Foods Inc. (Tokyo, Japan). Low trans-fatty acids unsalted margarine (ExtremeNeo) was from Marubishi Co., Ltd. (Kumamoto, Japan). Gluten was from Glico Nutrition Co., Ltd. (Osaka, Japan). Skim Milk Powder was from Yotsuba Milk Products Co., Ltd. (Hokkaido, Japan). Sucrose was from Wako Pure Chemical Industries, Ltd. (Osaka, Japan). Amylose from potato was from Sigma-Aldrich Co., LLC (USA). Amylopectin hydrate from waxy corn was from Tokyo Chemical Industry Co., Ltd. (Tokyo, Japan). All other chemicals were of analytical grade.

\subsection{Yeast}

Strain YTPR1 isolated from pear Red Bartlett fruits harvested in Yamagata, Japan was used in the study. Loopful strains $(2 \mathrm{mg})$ sub-cultured in YPD plate medium (1\% yeast extract, $2 \%$ polypeptone, $2 \%$ D-glucose, and $2 \%$ agar) were suspended in $1 \mathrm{ml}$ of sterilized water. A $200 \mu \mathrm{l}$ of suspension was incubated with shaking at $120 \mathrm{rpm}$ at $30{ }^{\circ} \mathrm{C}$ for $48 \mathrm{~h}$ in $300 \mathrm{ml}$ of YPD liquid culture medium, and then these were centrifuged at 8,000 rpm for 10 min at $20{ }^{\circ} \mathrm{C}$. Cells were washed with sterilized distilled water. After these were centrifuged at the same 
condition, cells were washed in the same way. Finally, these treatments were repeated again. Cells (the moisture content: about $80 \%$ ) obtained were frozen at $-28{ }^{\circ} \mathrm{C}$ for 7 days, and then were used for bread making.

\subsection{Determination of Moisture Contents on Rice Flours}

Moisture contents of rice flours were measured at $180{ }^{\circ} \mathrm{C}$ for $10 \mathrm{~min}$ using a Moisture Determination Balance (FD-600, Kett Electric Laboratory, Tokyo, Japan).

\subsection{Determination of Apparent Amylose Contents on Rice Flours}

Apparent amylose contents of rice flours were determined by colorimeteric method. That is, $5 \mathrm{mg}$ of flour samples was collected in $5 \mathrm{ml}$ of measuring flask, and was added $0.5 \mathrm{ml}$ of distilled water. These were mixed with $0.1 \mathrm{ml}$ of $2.5 \mathrm{M} \mathrm{NaOH}$, and then were melted on a hot water bath. After cooling, mixture was neutralized with $0.25 \mathrm{ml}$ of $1 \mathrm{M} \mathrm{HCl}$, and then was filled up to $5 \mathrm{ml}$ with distilled water. A $0.1 \mathrm{ml}$ of this solution was sequentially mixed with $0.1 \mathrm{ml}$ of $2 \%$ potassium iodide- $0.2 \%$ iodine solution and $0.8 \mathrm{ml}$ of distilled water in an Eppendorf tube. Absorbance of solution was measured at $660 \mathrm{~nm}$. On the other hand, $10 \mathrm{mg}$ of amylose or amylopectin was separately collected in $10 \mathrm{ml}$ of measuring flask, and was added $1.0 \mathrm{ml}$ of distilled water. After addition $0.2 \mathrm{ml}$ of $2.5 \mathrm{M} \mathrm{NaOH}$, mixture was melted on a hot water bath. After cooling, mixture was neutralized with $0.5 \mathrm{ml}$ of $1 \mathrm{M} \mathrm{HCl}$, and then filled up to $10 \mathrm{ml}$ with distilled water. Mixture was mixed amylose or amylopectin solutions at specified mixing ratio was used for preparation of calibration curve.

\subsection{Determination of Damaged Starch Contents on Rice Flours}

Damaged starch contents of rice flours were measured by acid solution process (Arisaka \& Yoshii, 1991). Rice flours (dried weight: $20 \mathrm{mg}$ ) were collected in $50 \mathrm{ml}$ of Falcon tubes, and then mixed with $2.0 \mathrm{ml}$ of $0.25 \mathrm{M} \mathrm{HCl}$. After shaking at $160 \mathrm{rpm}$ for $2 \mathrm{~h}$ at $55^{\circ} \mathrm{C}$, mixture was centrifuged at $2,400 \times \mathrm{g}$ for $20 \mathrm{~min}$ at $20{ }^{\circ} \mathrm{C}$. Supernatants were used for measurement of total sugar contents by phenol-sulfuric acid method. Total sugar contents were calculated by calibration curve used glucose. Starch damage degree was calculated as following equation.

$$
\text { Starch damage degree }(\%)=\frac{\text { Glucose content of suparnatant }}{20} \times 100
$$

\subsection{Bread Making}

Basic ingredients for bread making using rice flours are as follows: rice flour (240 g), sucrose (13 g), salt (4 g), unsalted margarine $(8 \mathrm{~g})$, frozen yeast $(13 \mathrm{~g})$, and water $(240 \mathrm{~g})$. In comparison, ingredients for bread making using bread flour are as follows: wheat flour $(240 \mathrm{~g})$, sucrose $(20 \mathrm{~g})$, salt $(4 \mathrm{~g})$, skim milk powder $(12 \mathrm{~g})$, unsalted margarine $(20 \mathrm{~g})$, dried yeast $(3 \mathrm{~g})$, and water $(170 \mathrm{~g})$. Besides, we have been confirmed that $13 \mathrm{~g}$ (wet weight) of yeast is equivalent to $3 \mathrm{~g}$ of dried ones as cell concentration in this experiment condition from the results of growth tests. Dough was prepared using an automatic home bakery (menu: natural yeast dough) (SD-BMS106, Panasonic Corp., Osaka, Japan). Dough obtained was secondary fermented at $35{ }^{\circ} \mathrm{C}$ for $60 \mathrm{~min}$ using a commercially available household steam convection-type oven (menu: fermentation) (Healsio AX-GX2, Sharp Co., Tokyo, Japan). Then, bread loaf was baked at $180{ }^{\circ} \mathrm{C}$ for $30 \mathrm{~min}$ using the same oven (menu: oven with preheating).

\subsection{Determination of Moisture Content on Crumb}

Breads after baking were cooled at room temperature for $1 \mathrm{~h}$, and then moisture contents of crumbs were measured at $140{ }^{\circ} \mathrm{C}$ for $15 \mathrm{~min}$ using a Moisture Determination Balance.

\subsection{Determination of Expansion Ratio}

Breads after baking were cooled at room temperature for $1 \mathrm{~h}$, and then loaf volumes were determined by rapeseed displacement method (Nagano et al., 2003). Expansion ratio was calculated as following equation.

$$
\text { Expansion ratio }(\%)=\frac{\text { Loaf volume after baking }\left(\mathrm{cm}^{3}\right)}{\text { Dough weight before baking }(\mathrm{g})} \times 100
$$

Specific volume was calculated as following equation.

$$
\begin{aligned}
& \text { Specific volume }\left(\mathrm{cm}^{3} / \mathrm{g}\right)=\frac{\text { Loaf volume after baking }\left(\mathrm{cm}^{3}\right)}{\text { Loaf weight after baking }(\mathrm{g})} \\
& 2.9 \text { Determination of Decreasing Rate of Baking }
\end{aligned}
$$

Loaf weight after baking was measured after cooling at room temperature for $1 \mathrm{~h}$. Decreasing rate of baking was calculated as following equation.

$$
\text { Decreasing rate of baking }(\%)=\frac{\text { Dough weight before baking }(\mathrm{g})-\text { Loaf weight after baking }(\mathrm{g})}{\text { Dough weight before baking }(\mathrm{g})} \times 100
$$




\subsection{Determination of Breaking Force}

Breads after baking were cooled at room temperature for $1 \mathrm{~h}$, and then breaking forces $(\mathrm{N})$ were measured using a rheometer (TPU-2, Yamaden Co., Ltd., Tokyo, Japan) equipped with a wedge-shaped plunger No. 49. Crumb samples $(40 \times 40 \times 20 \mathrm{~mm})$ from center of each slice were compressed up to $25 \%$ deformation at a compression speed of $10 \mathrm{~mm} / \mathrm{s}$. Six replicates of crumb samples were analyzed and the mean was reported.

\subsection{Color Measurement}

Breads after baking were cooled at room temperature for $1 \mathrm{~h}$, and then color analysis was performed using a colorimeter (NR-11A, Nippon Denshoku Industries Co., Ltd., Tokyo, Japan) with illuminant D65 calibrated to black and white standards. The CIE $L^{*} a^{*} b^{*}$ system was used as the relation to human eye response to color. Color was measured on five different spots in vertices and sides of crusts and crumbs on breads, and results were shown as the mean of these measurements. Moreover, color difference $\left(\Delta E^{*} a b\right)$ was calculated by following equation as a reference of the color on bread prepared using commercially available dried yeast.

$$
\Delta E^{*} a b=\left[\left(\Delta L^{*}\right)^{2}+\left(\Delta a^{*}\right)^{2}+\left(\Delta b^{*}\right)^{2}\right]^{1 / 2}
$$

Whiteness and brownness index were also calculated as described by Ulziijargal et al. (2013) and Shittu et al. (2007), respectively.

$$
\begin{gathered}
\text { Whiteness index }=100-\left[\left(100-L^{*}\right)^{2}+a^{*^{2}}+b^{*^{2}}\right]^{1 / 2} \\
\text { Brownness index }=[100 \times(\mathrm{X}-0.31)] / 0.17 \\
\text { where, } \mathrm{X}=\left(a^{*}+1.75 \times L^{*}\right) /\left(5.645 \times L^{*}+a^{*}-3.012 \times b^{*}\right)
\end{gathered}
$$

\subsection{Sensory Evaluation}

Breads after baking were cooled at room temperature for $1 \mathrm{~h}$, cut into a thickness of $1.5 \mathrm{~cm}$ using a home slicer (RLS-S19, Remacom Co., Ltd., Shizuoka, Japan), and then were used for sensory evaluation. Sensory qualities of breads were evaluated as described by the Japan Yeast Industry Association (1996) on the basis of appearance (specific volume, baking color, balanced shape, and crust) and crumb (grain, hue, texture, flavor, and taste) by a panel of 4 panelists on a 5-point Hedonic scale.

\subsection{Statistical Analysis}

Except for determination of breaking force and color, all experiment results were presented as means of 3 parallel replicates using independent 3 samples.

\section{Results and Discussion}

\subsection{Moisture Contents of Rice Flours}

At first, moisture contents of rice flours used in the study were measured. As a result, contents ranged from about 9.0 to $12.8 \%$ as follows: Koshihikari (12.8\%), Hitomebore (11.4\%), Hinohikari (12.5\%), Akitakomachi (9.0\%), and Haenuki (11.5\%), respectively. When bread is made from bread flour, it is known that moisture content of flour is desirable at $14 \%$ or less (Atwell, 2001). It suggested that rice flours used were suitable for bread making as ingredients in moisture contents. We do not know harvesting period, storage methods and times, milling methods and times, and drying methods of rices and so on. It may be related a wide range of conditions on moisture contents of rice flours.

\subsection{Apparent Amylose Contents of Rice Flours}

Apparent amylose contents differed among these flours, ranging from about 12.1 to $19.9 \%$ as follows: Koshihikari (15.1\%), Hitomebore (19.9\%), Hinohikari (12.1\%), Akitakomachi (17.8\%), and Haenuki (16.3\%), respectively. Amylose content of rice varies from its cultivars, ranging 0 to about $35 \%$. Generally, it is said that it is adequate for bread making to use rice flours with amylose contents about $17-20 \%$. There is a tendency to become soft and caving bread on low-amylose rice with the contents about 5-15\% as rice cultivar Milky Queen. On the contrary, it becomes hard on the surface of breads, although volume of bread increase when high-amylose rice about 25-35\% as Yumetoiro is used (Yoza et al., 2008). Amylose contents of rice flours affect bread-making qualities of rice breads (Aoki et al., 2010; Takahashi et al., 2009).

\subsection{Damaged Starch Contents of Rice Flours}

Damaged starch contents of rice flours were determined by acid solution process. As a result, contents were about $22 \%$ regardless to the kinds of rice cultivars as follows: Koshihikari $(21.1 \%)$, Hitomebore (22.3\%), Hinohikari (22.8\%), Akitakomachi (22.8\%), and Haenuki (22.8\%). Takahashi et al. (2009) prepared rice flours from 16 different rice cultivars using a jet mill for making rice breads, and reported that damaged starch contents 
of these flours ranged about 1.4-6.0\%. Aoki et al. (2010) prepared rice flours from 9 high-yielding rice cultivars and Koshihikari using a jet mill for making bread with wheat gluten. Contents of these flours were fairly low about $1.3-3.2 \%$. It is desirable that particles of rice flours are moderately fine and damaged starch contents are low for bread making using wheat gluten. Damaged starch contents and particle size distribution of rice flours are often utilized for one of quality index of its flours (Araki, 2010). In this regard, it may be not suitable for bread making, as damaged starch contents of rice flours used in the study are fairly high in comparison with contents of rice flours reported in the previous papers. However, it is reported that flour containing damaged starch about $10-20 \%$ is suitable when bread make from wheat and rice composite flour and gluten (8:2) (Takano et al., 1986). High content of damaged starch is decomposed by amylase in wheat flour, and then maltose produced is used by yeast for fermentation. In general, decomposition of maltose on wild-type $S$. cerevisiae is weak. However, yeast strain YTPR1 utilizes maltose as well as glucose, fructose, and sucrose. In fact, dough prepared using bread flour leavened in all of conditions for making not only French and white breads but also sweet breads, suggesting that damaged starches in rice flours are used to produce maltose by strain YTPR1.

\subsection{Bread Making}

First, bread was made from rice flour of Koshihikari cultivar that accounted for about $36 \%$ of total domestic production in Japan. As a result, dough hardly expanded or has caused caving/cave-in. Rice flour is gluten-free, so it could not retain gas produced during fermentation in dough or leavening dough after fermentation could not maintain for baking in the basic ingredients.

Next, gluten powder (48 g) was added about $20 \mathrm{wt} . \%$ based on rice flour $(240 \mathrm{~g})$, and breads were made from five species of rice flours in the same way. In this case, the amount of water was $215 \mathrm{~g}$. Width of bread was about $9.0 \times 12.0$ in any rice flour because of use of an attached bread case of an automatic home bakery. Maximum and minimum heights of loaves differed from each other as follows: 13.0 and $8.2 \mathrm{~cm}$ (Koshihikari), 11.6 and $8.4 \mathrm{~cm}$ (Hitomebore), 12.5 and $10.0 \mathrm{~cm}$ (Hinohikari), 11.0 and $8.0 \mathrm{~cm}$ (Akitakomachi), and 13.0 and 8.6 cm (Haenuki), respectively (Figure 1). Breads made from Hinohikari and Haenuki flours had relatively well-balanced shape (Figures 1D and $1 \mathrm{~F}$ ), and fine-grained bubble membranes uniformly and homogeneously spread in crumbs (Figures 1J and 1L), although appearance and cross section of crumbs on breads were inferior to those on bread made from bread flour and commercially available baker's dried yeast. On the other hand, breads made from Koshihikari, Hitomebore, and Akitakomachi flours were not enough to expand (Figures 1B, $1 \mathrm{C}$, and 1E). Bubble membranes (grains) were relatively large and non-uniformly or heterogeneously spread in crumbs of breads, resulting in coarse and uneven grains (Figures 1H, 1I, and 1K). Any bread made from flour has caused caving/cave-in. In particular, bread made from Akitakomachi flour largely sank in center of crumb (Figure 1K). It suggested that dough could not fully form gluten network capable of expanding and retain gas produced during fermentation, resulting in bread with lower height and coarse and uneven grains. In comparison with bread made from bread flour, heights of breads made from rice flours and strain YTPR1 were low and crumbs had coarse grain in all cases.

The amount of water affects bread characteristics including expansion ratio and texture of bread. The amount of water added in dough was regulated in consideration of moisture contents of rice flours. As a result, optimal amount of water became clear as follows: $225 \mathrm{~g}$ (Koshihikari), $240 \mathrm{~g}$ (Hitomebore), $215 \mathrm{~g}$ (Hinohikari), $250 \mathrm{~g}$ (Akitakomachi), and $240 \mathrm{~g}$ (Haenuki), respectively. It was observed negative correlation between the amount of water added in dough and moisture contents of rice flours $\left(\mathrm{R}^{2}=0.7392\right)$. And it was investigated correlation between the amount of water and amylose contents of rice flours, and was observed correlation with $\mathrm{R}^{2}=0.7029$. Appearance and cross section of crumbs on breads prepared after regulation of the amount of water added in dough are shown in Figure 2. Except for bread made from Akitakomachi flour, breads largely expanded similar to that made from bread flour. The maximum and minimum heights of loaves were as follows: 14.5 and $9.3 \mathrm{~cm}$ (Koshihikari), 13.5 and $9.8 \mathrm{~cm}$ (Hitomebore), 14.5 and $10.5 \mathrm{~cm}$ (Hinohikari), 11.5 and $6.5 \mathrm{~cm}$ (Akitakomachi), and 16.0 and $11.3 \mathrm{~cm}$ (Haenuki), respectively (Table 1). Bread made from Koshihikari flour had thick skin and crisp skin surface in crust (Figure 2B). Loaf was spread largely, but occurrences of big crack caused by baking. Crumb near crust had relatively dense grain. Breads made from Hitomebore and Hinohikari flours had thin skins and crisp skin surfaces in crusts (Figures 2C and 2D), but bread made from Hitomebore flour has caused caving/cave-in by baking. Fine-grained bubble membranes uniformly and homogeneously spread in crumbs of breads (Figures 2I and 2J). Bread made from Akitakomachi flour had thick skin and crisp skin surface in crust (Figure 2E). Loaf overall spread, but crumb had dense and close grain (Figure 2K). Bread made from Haenuki flour had thin skin and crisp skin surface in crust (Figure 2F). Loaf was spread largely and bubble membranes were large but non-uniformly and heterogeneously spread in crumb of bread (Figure 2L). Among them, bread made from Hinohikari flour had good expansion and superior crumb internal quality. Damaged starch on rice 
flours increase water absorption in dough compared with intact starch, resulting in insufficient leavening of dough and low expansion of bread (Arisaka et al., 1992). That is, damaged starch contents of rice flours affect expansion of bread. At present, rice flours are produced by such as dry-milling or wet-milling methods. The former is method produce flour as roller milled flour, pin milled flour, and friction milled flour, and the latter is one produce ones as stamp milled flour, press roller milled flour, and disk-milled flour. Difference of milling method of rice affect damaged starch contents and distribution of particle size of flours. It may become possible to produce high qualities of breads using rice flours by improvement of milling method and reducing of damaged starch contents.

\subsection{Bread Property}

Moisture contents of central slice of crumbs on breads prepared after regulation of the amount of water added in dough are shown in Table 1. Contents differed among these breads, ranging from about 46.0 to $51.5 \%$ as follows: Koshihikari (46.6\%), Hitomebore (48.3\%), Hinohikari (46.0\%), Akitakomachi (51.5\%), and Haenuki (46.3\%), respectively. On the other hand, content on bread made from bread flour was low about $43.4 \%$. It suggested that moisture was hard to evaporate during baking, as damaged starch contents of rice flours used in the study were high, and dough prepared using flours with higher damaged starch contents tended to become harder.

Loaves volumes were measured by rapeseed displacement method. As a result, volumes ranged about 1088.1-1782.9 $\mathrm{cm}^{3}$ (Table 1), and were in decreasing order as follows: Haenuki, Koshihikari, Hinohikari, Hitomebore, and Akitakomachi. Volumes of all loaves did not amount to that on bread made from bread flour.

Expansion ratios of these loaves were calculated. Ratio was highest in loaf made from Haenuki flour, and was in lowering order as follows: Koshihikari, Hinohikari, Hitomebore, and Akitakomachi flours (Table 1). These did not amount to that on loaf made from bread flour. It was no correlation between expansion ratios of loaves and amylose contents of rice flours $\left(\mathrm{R}^{2}=0.3458\right)$. Weights of these loaves were measured using an analytical balance, and these ranged about 504.9-544.1 g (Table 1). Among them, weight of loaf made from Akitakomachi flour was most heavy, and was in lowering order as follows: those of loaves made from Hitomebore, Hinohikari, Haenuki, and Koshihikari flours.

Specific volume is used as one of important parameter to evaluate quality of bread to correspond to softening of crumb on bread (Boye et al., 2010; Tronsmo et al., 2003). Specific volumes of loaves were calculated, and these ranged from about 2.00 to $3.51 \mathrm{~cm}^{3} / \mathrm{g}$ (Table 1). Loaf made from Haenuki flour had most high specific volume among these loaves, and volumes were in lowering order as follows: Koshihikari $\left(3.19 \mathrm{~cm}^{3} / \mathrm{g}\right)$, Hinohikari $(3.02$ $\left.\mathrm{cm}^{3} / \mathrm{g}\right)$, Hitomebore $\left(2.54 \mathrm{~cm}^{3} / \mathrm{g}\right)$, and Akitakomachi $\left(2.00 \mathrm{~cm}^{3} / \mathrm{g}\right)$. Specific volumes of these loaves were fairly low in comparison with that made from bread flour. It was investigated correlation between specific volumes of breads and amylose contents of rice flours, and there are no correlation about $\mathrm{R}^{2}=0.2574$. According to China Grain Products Research and Development Institute, it is reported that specific volume of standard bread is 6 $\mathrm{cm}^{3} / \mathrm{g}$, and should not be less than $3.5 \mathrm{~cm}^{3} / \mathrm{g}$ (Lin et al., 2009). On the contrary, Sluimer (2005) reported that specific volume below $4 \mathrm{~cm}^{3} / \mathrm{g}$ affected quality of bread. It is important to develop breads with high specific volumes, as it is preferred soft bread in most cases.

Weight losses on loaves made from rice flours were calculated. Loss on loaf made from bread flour was highest among these loaves tested, suggesting bread with soft texture (Table 1). The losses were in lowering order as follows: loaves made from Haenuki (10.1\%), Hinohikari (10.6\%), Hitomebore (8.7\%), Koshihikari (8.3\%), and Akitakomachi (7.2\%) flours. It is known that weight loss on white bread is about $10-12 \%$, and bread with lower loss become harder. It was suggested that crumbs of loaves made from Haenuki and Hinohikari flours were soft; these had superior internal characteristics such as crumb homogeneity and geometry of its bubbles (Figures 2D, $2 \mathrm{~F}, 2 \mathrm{~J}$, and $2 \mathrm{~L}$ ). 


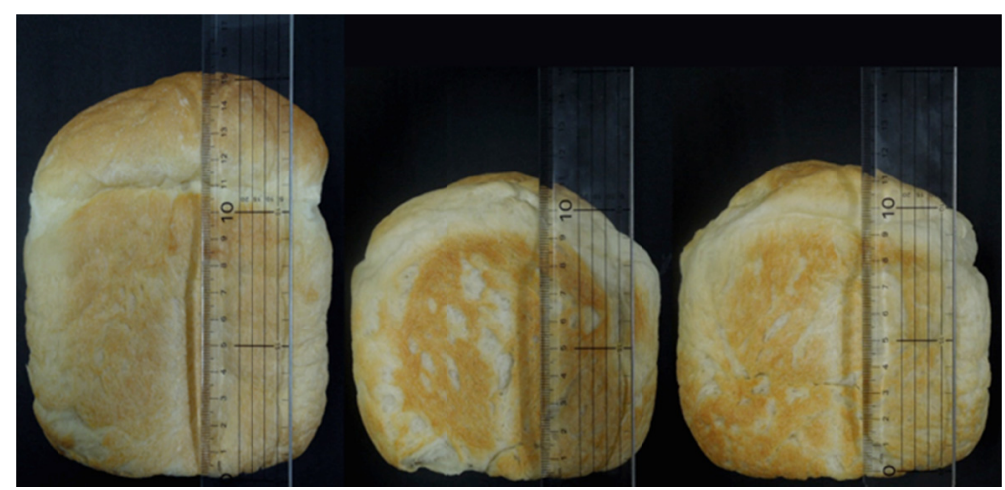

(A)

(B)

(C)

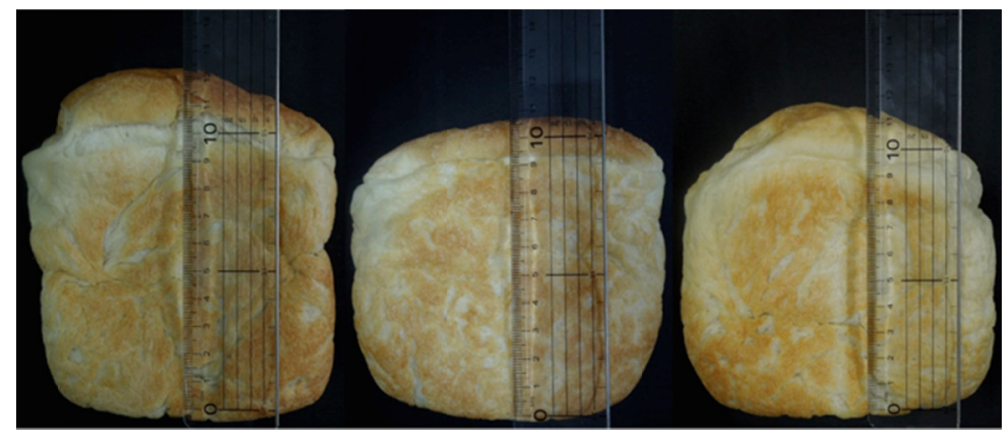

(D)

(E)

(F)

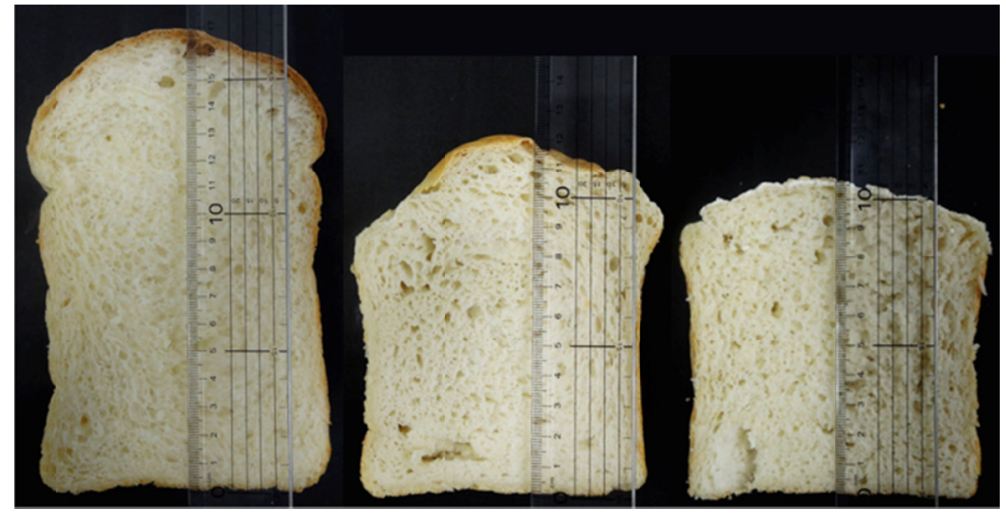

(G)

(H)

(I)

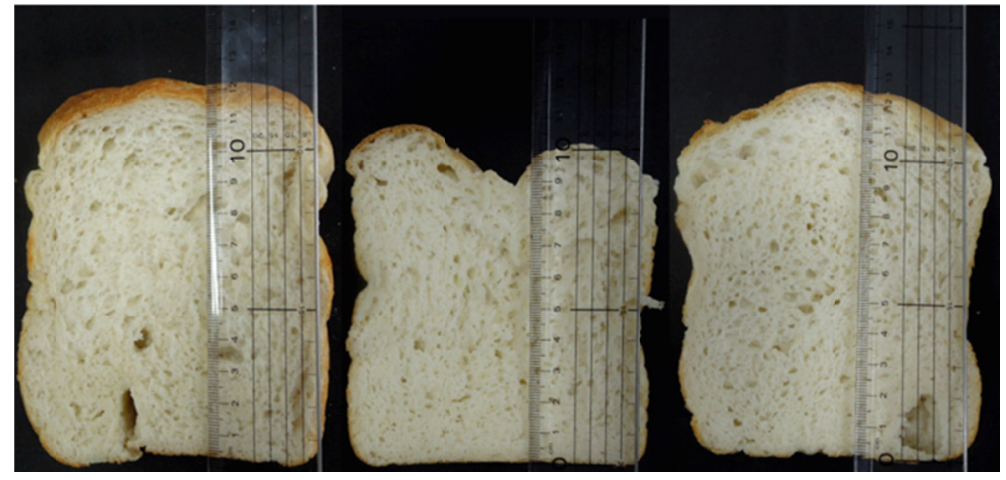

(J)

(K)

(L)

Figure 1. Breads (A-F) and its cross sections of crumbs (G-L) made from rice flours

Note. (A, G) commercially available bread flour, (B, H) Koshihikari flour, (C, I) Hitomebore flour, (D, J) Hinohikari flour, (E, K) Akitakomachi flour, (F, L) Haenuki flour. 


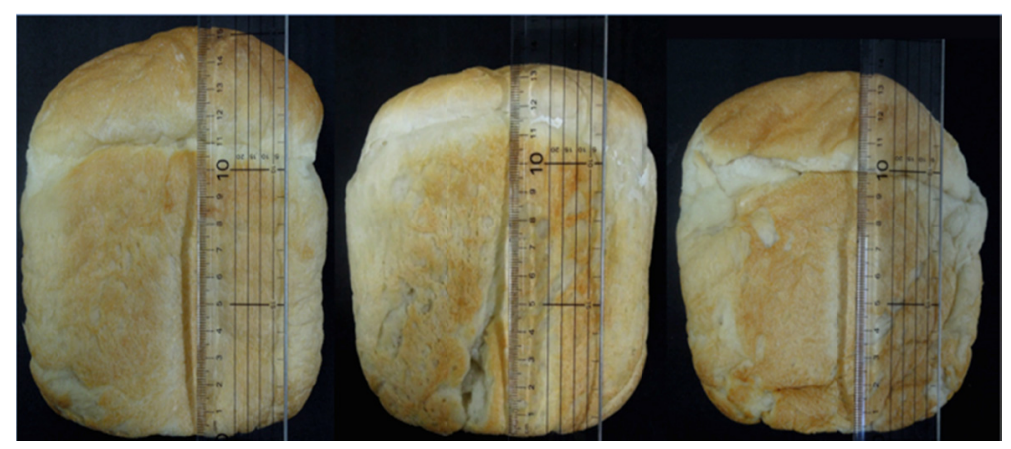

(A)

(B)

(C)

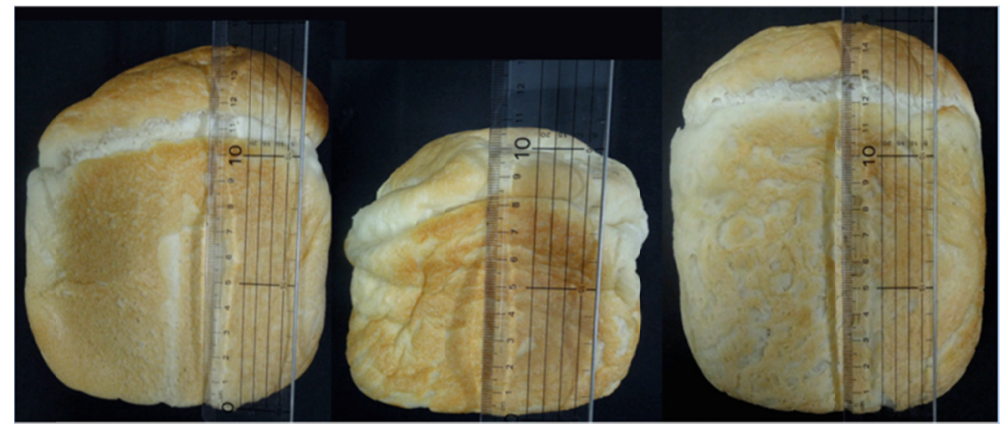

(D)

(E)

(F)

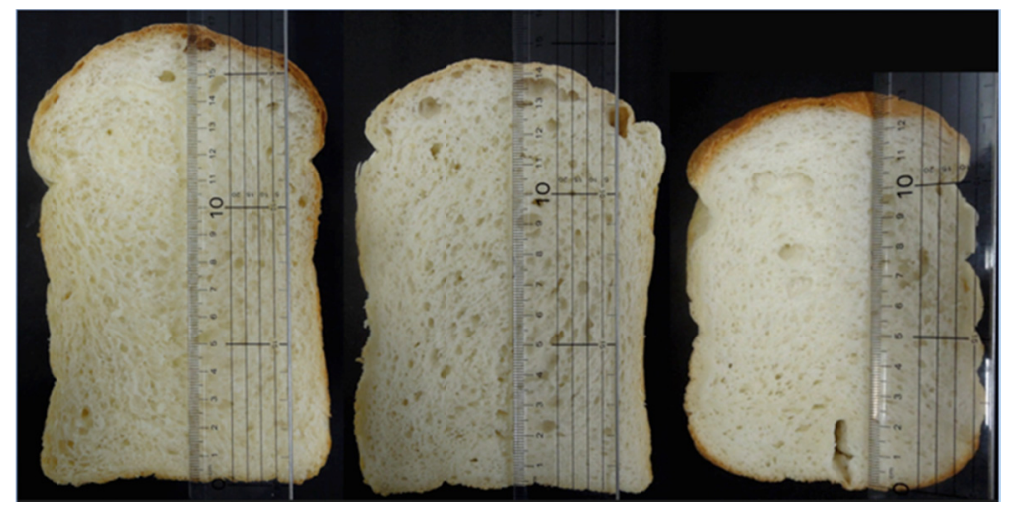

(G)

(H)

(I)

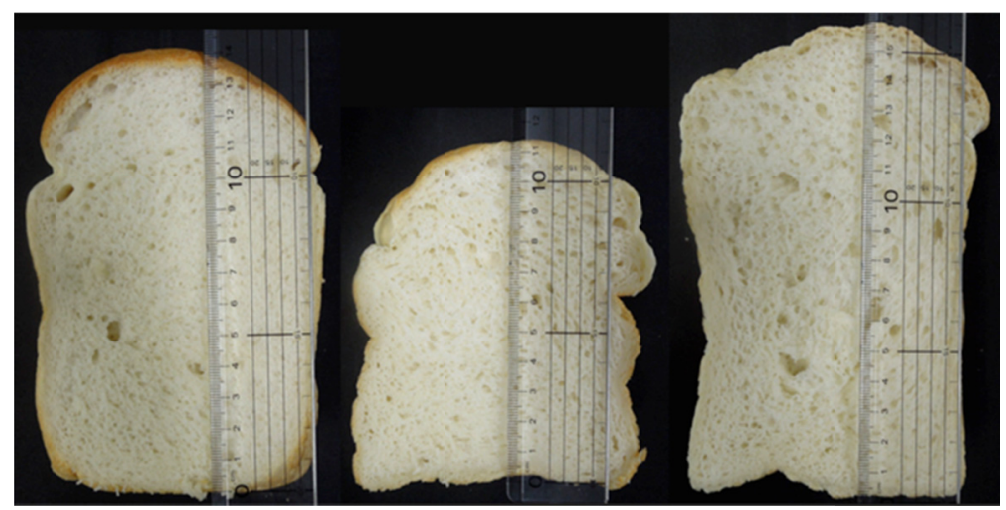

(J)

(K)

(L)

Figure 2. Breads (A-F) and its cross sections of crumbs (G-L) made from rice flours after adjustment of amount of water that were added in doughs

Note. (A, G) commercially available bread flour, (B, H) Koshihikari flour, (C, I) Hitomebore flour, (D, J) Hinohikari flour, (E, K) Akitakomachi flour, (F, L) Haenuki flour. 
Breaking forces of loaves made from rice flours were measured. Among these loaves, loaf made from Hitomebore flour showed highest force about $2.43 \mathrm{~N}$ (Table 1), indicating more closed internal structure having smaller crumb bubbles and higher crumb cohensiveness for insufficient leavening of dough (Figures $2 \mathrm{C}$ and 2I). It may be supported by properties such as high moisture content and low expansion ratio, specific volume, and weight loss obtained (Table 1). On the other hand, forces of loaves made from Hinohikari and Haenuki flours were relatively low, on the basis of low moisture contents and comparatively high expansion ratios, specific volumes, and weight losses. Surprisingly, loaf made from Akitakomachi flour had lowest and almost the same breaking force as that made from bread flour, in spite of low expansion ratio, specific volume, and weight loss (Table 1). It may be due to high moisture content of crumb and small, uniformly, and homogeneously spreading fine-grained bubble membranes on one side of it (Figure 2K). There are no correlation between breaking forces of loaves and amylose contents of rice flours $\left(\mathrm{R}^{2}=0.2478\right)$.

Color characteristics on vertices of crusts, sides of crusts, and crumbs of loaves made from rice flours were investigated. On vertices of crusts, loaves made from Koshihikari, Hinohikari, and Haenuki flours had significantly higher $L^{*}$ values, and those made from Hitomebore and Akitakomachi flours had relatively higher ones in comparison with that made from bread flour (Table 1). Vertices of crusts on loaves made from rice flours showed whitish color compared with that on loaf made from bread flour. The $a^{*}$ values on loaves made from rice flours were considerably low about 5.75-10.99 in comparison with that on loaf made from bread flower $\left(a^{*}=\right.$ 12.88): vertices of crusts on loaves made from rice flours had light red colors. The $b^{*}$ values differed among these loaves made from rice flours as follows: Koshihikari (28.17), Hitomebore (25.45), Hinohikari (26.92), Akitakomachi (21.37), and Haenuki (23.91). The $\Delta E^{*} a b$ values on loaves made from rice flours were calculated and color difference was evaluated to loaf made from bread flour as follows: Hitomebore (appreciable), Akitakomachi (much), and Koshihikari, Hinohikari, and Haenuki (very much), respectively. Next, whiteness indexes of loaves were calculated. As a result, loaf made from bread flour showed lowest index among these loaves tested (Table 1). On the contrary, index was in higher order as follows: Hitomebore, Akitakomachi, Koshihikari, Hinohikari, and Haenuki. Brownness indexes of loaves were also calculated. Loaf made from bread flour showed highest index among these loaves (Table 1). Index was in lowering order as follows: Hitomebore, Koshihikari, Hinohikari, Akitakomachi, and Haenuki. On sides of crusts, loaves made from Koshihikari and Akitakomachi flours had higher $L^{*}$ values, but those made from Hinohikari, Haenuki, and Hitomebore flours had lower ones than that made from bread flour (Table 1). The $a^{*}$ values differed among these loaves made from rice flours.

In comparison with that on loaf made from bread flour, value on loaf made from Hitomebore flour was fairly high, but those on loaves made from other rice cultivar flours were low. Only loaf made from Akitakomachi flour had slightly high $b^{*}$ value compared with that made from bread flour, but others had fairly low ones. The $\Delta E^{*} a b$ values were calculated, and color difference was evaluated to loaf made from bread flour as follows: Koshihikari, Hinohikari, Akitakomachi, and Haenuki (appreciable), and Hitomebore (much), respectively. Whiteness indexes were calculated. Except for loaf made from Hitomebore flour, other loaves had whitish-colored crusts compared with that made from bread flour. From results of brownness indexes, it found that loaf made from Hitomebore flour had darker brown colored crust (foxy brown colored crust) in comparison with that made from bread flour, but loaves made from other rice flours had light brown colored crusts (golden brown colored crusts) (Table 1, Figure $2 \mathrm{C}$ ). On crumbs, $L^{*}$ values of all loaves made from rice flours were significantly higher than that of loaf made from bread flour, indicating that loaves made from rice flours had whitish-colored crumbs. However, $a^{*}$ values of loaves made from rice flours were lower than that of loaf made from bread flour. On the other hand, except for loaf made from Koshihikari flour, $b^{*}$ values of loaves made from rice flours were higher than that of loaf made from bread flour (Table 1). By $\Delta E^{*} a b$ values, color difference on crumbs of loaves was evaluated as follows: Koshihikari and Haenuki (much) and Hitomebore, Hinohikari, and Akitakomachi (Very much), respectively. Next, whiteness indexes were calculated. As a result, any loaf made from rice flours showed higher indexes than that made from bread flour. Indexes were especially high on loaves made from Hitomebore, Hinohikari, and Akitakomachi flours, suggesting that these loaves had strongly whitish-colored crumbs among these loaves made from rice flours (Figures 2I, 2J, and 2L). Browning in baked foods such as breads is caused by caramelization and Maillard reaction during baking. Colors on breads are especially important quality indicator, as visual colors of crusts and crumbs on loaves are relevant to acceptance and taste (Chattopadhyay et al., 2013). 
Table 1. Characteristics of breads made from rice flours and wild-type S. cerevisiae strain YTPR1 isolated from pear Red Bartlett fruits

\begin{tabular}{|c|c|c|c|c|c|c|c|}
\hline & & $\begin{array}{l}\text { Commercially } \\
\text { available bread flour }\end{array}$ & $\begin{array}{l}\text { Koshihikari } \\
\text { flour }\end{array}$ & $\begin{array}{l}\text { Hitomebore } \\
\text { flour }\end{array}$ & $\begin{array}{l}\text { Hinohikari } \\
\text { flour }\end{array}$ & $\begin{array}{l}\text { Akitakomachi } \\
\text { flour }\end{array}$ & $\begin{array}{l}\text { Haenuki } \\
\text { flour }\end{array}$ \\
\hline \multicolumn{2}{|c|}{ Dough weight (g) } & 469.0 & 551.0 & 566.0 & 541.0 & 576.0 & 566.0 \\
\hline \multicolumn{2}{|l|}{ Loaf weight (g) } & 408.0 & 504.9 & 516.8 & 511.6 & 544.1 & 507.9 \\
\hline \multicolumn{2}{|c|}{ Loaf volume $\left(\mathrm{cm}^{3}\right)$} & 1832.4 & 1610.6 & 1312.6 & 1545.1 & 1088.1 & 1782.9 \\
\hline \multicolumn{2}{|c|}{ Loaf height max (cm) } & 17.0 & 14.5 & 13.5 & 14.5 & 11.5 & 16.0 \\
\hline \multicolumn{2}{|c|}{ Loaf height $\min (\mathrm{cm})$} & 13.0 & 9.3 & 9.8 & 10.5 & 6.5 & 11.3 \\
\hline \multicolumn{2}{|c|}{ Moisture (\%) } & 43.4 & 46.6 & 48.3 & 46.0 & 51.5 & 46.3 \\
\hline \multicolumn{2}{|c|}{ Expansion ratio (\%) } & 390.7 & 292.3 & 231.9 & 285.6 & 188.9 & 315.0 \\
\hline \multicolumn{2}{|c|}{ Specific volume $\left(\mathrm{cm}^{3} / \mathrm{g}\right)$} & 4.49 & 3.19 & 2.54 & 3.02 & 2.00 & 3.51 \\
\hline \multicolumn{2}{|c|}{ Weight loss $(\%)$} & 13.0 & 8.3 & 8.7 & 10.6 & 7.2 & 10.1 \\
\hline \multicolumn{2}{|c|}{ Breaking force $(\mathrm{N})$} & 1.52 & 1.90 & 2.43 & 1.84 & 1.64 & 1.76 \\
\hline \multicolumn{8}{|l|}{ Color } \\
\hline \multirow[t]{3}{*}{ Vertex of crus } & $L^{*}$ & 66.73 & 78.67 & 69.96 & 79.36 & 69.97 & 81.19 \\
\hline & $a^{*}$ & 12.88 & 10.75 & 10.99 & 9.88 & 5.75 & 8.22 \\
\hline & $b^{*}$ & 26.32 & 28.17 & 25.45 & 26.92 & 21.37 & 23.91 \\
\hline \multicolumn{2}{|l|}{$\Delta E^{*} a b$} & - & Very much & Appreciable & Very much & Much & Very much \\
\hline \multicolumn{2}{|c|}{ Whiteness index } & 55.67 & 63.07 & 59.12 & 64.67 & 62.70 & 68.49 \\
\hline \multicolumn{2}{|c|}{ Brownness index } & 63.44 & 53.62 & 56.01 & 49.89 & 41.84 & 41.75 \\
\hline \multirow[t]{3}{*}{ Side of crust } & $L^{*}$ & 72.17 & 76.55 & 65.03 & 70.86 & 77.24 & 69.33 \\
\hline & $a^{*}$ & 7.61 & 6.90 & 8.61 & 6.50 & 7.34 & 5.07 \\
\hline & $b^{*}$ & 22.86 & 19.66 & 20.96 & 18.57 & 23.64 & 16.07 \\
\hline \multicolumn{2}{|l|}{$\Delta E^{*} a b$} & - & Appreciable & Much & Appreciable & Appreciable & Appreciable \\
\hline \multicolumn{2}{|c|}{ Whiteness index } & 63.19 & 68.63 & 58.33 & 64.84 & 66.37 & 65.01 \\
\hline \multicolumn{2}{|c|}{ Brownness index } & 45.20 & 35.81 & 48.02 & 36.63 & 42.90 & 31.28 \\
\hline \multirow[t]{3}{*}{ Crumb } & $L^{*}$ & 70.88 & 79.46 & 87.37 & 81.36 & 86.60 & 80.44 \\
\hline & $a^{*}$ & -0.35 & -0.80 & -0.69 & -0.59 & -0.66 & -0.64 \\
\hline & $b^{*}$ & -5.18 & -6.46 & -3.62 & -3.28 & -2.89 & -4.78 \\
\hline \multicolumn{2}{|l|}{$\Delta E^{*} a b$} & - & Much & Very much & Very much & Very much & Much \\
\hline \multicolumn{2}{|c|}{ Whiteness index } & 70.42 & 78.45 & 86.84 & 81.06 & 86.28 & 79.85 \\
\hline
\end{tabular}

Sensory analysis was performed, and qualities of breads were evaluated in accordance with scorecard on the Japan Yeast Industry Association (1996). Specific volumes of loaves made from rice flours were lower than that of loaf made from bread flour (Table 2). Baking colors of loaves made from Hitomebore and Hinohikari flours were similar to that of loaf made from bread flour, but loaves made from Koshihikari, Akitakomachi, and Haenuki flours had appearances with unevenness in baking (Figures 2B, 2E, and 2F). Crust on loaf made from Hinohikari flour was best among these loaves tested. Loaves made from Koshihikari, Hinohikari, and Haenuki flours showed high scores in grain, as fine-grained bubble membranes uniformly and homogeneously spread in crumbs (Figures 2H, 2J, and 2L). Colors on loaves made from Akitakomachi and Haenuki flours and texture on those made from Hinohikari and Haenuki flours were better. Loaf made from Hinohikari flour had good flavor, and those made from Koshihikari, Hinohikari, and Haenuki flours had good tastes. It was evaluated that bread made from Hinohikari flour was bread having total points closest to that made from bread flour among these breads tested, suggesting it was highly estimated on the basis of appearance and crumb on bread. 
Table 2. Quality evaluation of breads made from rice flours and wild-type $S$. cerevisiae strain YTPR1 isolated from pear Red Bartlett fruits

\begin{tabular}{|c|c|c|c|c|c|c|c|c|c|c|c|}
\hline Flour & $\begin{array}{l}\text { Specific } \\
\text { volume }\end{array}$ & $\begin{array}{l}\text { Baking } \\
\text { color }\end{array}$ & $\begin{array}{l}\text { Balanced } \\
\text { shape }\end{array}$ & Crust & Grain & Hue & Texture & Flavor & Taste & $\begin{array}{l}\text { Total } \\
\text { points }\end{array}$ & Ranking \\
\hline Wheat & $16 \mathrm{D}$ & $7.8 \mathrm{C}$ & $4.4 \mathrm{C}$ & $4.0 \mathrm{C}$ & $8.1 \mathrm{C}$ & $4.4 \mathrm{C}$ & $4.1 \mathrm{C}$ & $12.0 \mathrm{C}$ & $11.5 \mathrm{C}$ & 72.3 & $\mathrm{C}$ \\
\hline Koshihikari & $10 \mathrm{E}$ & $6.3 \mathrm{D}$ & $4.3 \mathrm{C}$ & $3.9 \mathrm{D}$ & $8.5 \mathrm{~B}$ & $4.1 \mathrm{C}$ & $4.0 \mathrm{C}$ & $11.0 \mathrm{C}$ & $12.0 \mathrm{C}$ & 64.1 & $\mathrm{D}$ \\
\hline Hitomebore & $10 \mathrm{E}$ & $7.4 \mathrm{C}$ & $4.3 \mathrm{C}$ & $4.3 \mathrm{C}$ & $8.2 \mathrm{C}$ & $4.3 \mathrm{C}$ & $4.3 \mathrm{C}$ & $11.0 \mathrm{C}$ & $11.0 \mathrm{C}$ & 64.8 & $\mathrm{D}$ \\
\hline Hinohikari & $10 \mathrm{E}$ & $7.4 \mathrm{C}$ & $4.0 \mathrm{C}$ & $4.8 \mathrm{~B}$ & $8.9 \mathrm{~B}$ & $3.9 \mathrm{D}$ & $4.7 \mathrm{~B}$ & $13.5 \mathrm{~B}$ & $12.0 \mathrm{C}$ & 69.2 & $\mathrm{D}$ \\
\hline Akitakomachi & $10 \mathrm{E}$ & $5.5 \mathrm{D}$ & $4.1 \mathrm{C}$ & $4.3 \mathrm{C}$ & $7.4 \mathrm{C}$ & $4.8 \mathrm{~B}$ & $4.4 \mathrm{C}$ & $11.0 \mathrm{C}$ & $10.0 \mathrm{D}$ & 61.5 & $\mathrm{D}$ \\
\hline Haenuki & $10 \mathrm{E}$ & $6.3 \mathrm{D}$ & $4.3 \mathrm{C}$ & $3.9 \mathrm{D}$ & $8.5 \mathrm{~B}$ & $4.5 \mathrm{~B}$ & $4.5 \mathrm{~B}$ & $10.5 \mathrm{D}$ & $12.8 \mathrm{C}$ & 65.3 & $\mathrm{D}$ \\
\hline
\end{tabular}

Takahashi et al. (2009) investigated effects of characteristics of rice cultivars on qualities of breads made from rice flours by analyzing amylose contents, damaged starch contents, and particle size compositions. It found that water absorption rate on 500FU (farinograph Brabender units) differed among its cultivars, and there was correlation between the rate and amylose contents of flours. They clarified that specific volumes and shapes of breads made from rice flours were different for kinds of rice flours, and these were correlated with amylose contents and viscogram properties of rice flours with gluten. Hardness on breads made from rice flours is also correlated with its amylose contents. They concluded that rice cultivars containing about $15-25 \%$ amylose are suitable for bread making using rice flours. Aoki et al. (2010) investigated properties of breads made from flours of high-yielding rice cultivars with gluten. Bread had not caused caving/cave in, and its specific volumes of loaves were same or higher than that of loaf made from Koshihikari flour. Among these rice flours, breads made from Moriroman flour with highest amylose content about 26.0\% and Kusahonami ones (amylose content about $16.5 \%$ ) with high gelatinization temperature were harder than that made from Koshihikari ones. On the other hand, there were no correlation between protein contents of these flours and specific volumes and hardness of breads. They suggested that high quality of bread could make from rice flour with amylose content about $20 \%$ and low gelatinization temperature.

Characteristics of starches on rice flours are different by milling techniques such as jet milling and stamp milling (Okunishi, 2015a, 2015b; Yoza et al., 2008). So bread-making qualities are affected by milling methods. Ogawa and Nagai (2011) investigated effect of milling methods on qualities of rice flours and properties of breads made from rice flours with gluten by straight method. As a result, there was a tendency to become small on particle size in rice with high moisture contents in the case of the same milling methods. Flours prepared by wet-jet milling and water-milling methods were suitable for bread making. When dough was prepared using coarse grained rice flours, gluten was not fully formed, resulting in lower gas retaining in loaf during baking. There were negative correlation between damaged starch contents or particle size of rice flours and specific volumes of breads. That is, rice flour with higher damaged starch content was not suitable for bread making. Yamazawa et al. (2012) reported effects of milling methods on qualities of breads made from rice cultivar Aichinokaori flours with gluten (8:2) using an automatic home bakery. From the results of loaf height, shape, specific volume, and compressive strength, flours prepared by hammer milling and blade-milling methods were not suitable for bread making. On the contrary, combination of roll and blade milling and blade milling methods after pectinase treatment of rice flour were suitable for bread making under their experimental conditions. They concluded that best conditions for making bread using its rice flour are as follows: low damaged starch content, low water absorption in dough, and high proportion of rice flour with particle size less than $63 \mu$ l. Shoji et al. (2012) evaluated powder and water absorption properties of rice flour prepared by different milling techniques. As a result, there were no relationships between particle diameter of starch and its properties on rice flour prepared by wet hammer milling method. However, rice flour with smaller particle diameters prepared by dry jet milling method showed high starch damage degree and gelatinization degree. Moreover, its water absorption velocity was slow and saturated water absorption became higher. It suggested that starch properties on rice flour affected water absorption property, as it was shown correlation between water absorption velocity coefficient and starch damage degree on its flour.

It is known that baking qualities and bread properties during storage are greatly influenced by the amount of water added in dough (Takahashi et al., 2011). In breads made from wheat flour, it is considered that conditions showing maximum viscosity about 500BU using Farinograph are the appropriate amount of water added in dough. On the other hand, there are some reports about bread made from rice flour with gluten in conditions showing about 500BU (Takahashi et al., 2009), and about bread made from mixture of rice flour and gluten and 
the amount of water at a ratio of 100:80 (Araki et al., 2009). Takahashi et al. (2011) prepared rice bread using mixture of rice flour and gluten at a ratio of 85:15, and investigated relationship between the amount of water and specific volume of loaf. It found that the amount of water in dough showing about 300BU resulted in largest specific volume of bread. Okunishi et al. (2012) tried to prepare breads using dough with various amounts of water and to evaluate the properties of these breads to develop method for determination of appropriate amount of water for making breads using rice flours. As a result, they concluded that conditions showing maximum viscosity about 400BU were the appropriate amount of water added in dough. Takahashi and Yukizaki (2011) investigated effect of gluten addition on bread made from rice flour (moisture content: $12.55 \%$; averaged particle size: $48.3 \mu \mathrm{m}$; damaged starch content: $4.2 \%$ ). Dough with lower content of gluten could not fully form gluten network capable of expanding, resulting in bread with lower height and coarse and uneven grains. In contrast, dough with high content of it could not retain gas produced during fermentation, causing caving by baking. It suggested that bread with highest specific volume could make using rice mixed flour containing final concentration of $11 \%$ of protein content in gluten.

\section{Conclusion}

In conclusion, we reported preparation and characterization of breads using rice flours from major five non-glutinous rice cultivars on market shares of Japan and S. cerevisiae strain YTPR1 isolated from pear Red Bartlett fruits to develop high qualities of rice flour breads. In comparison with bread made from bread flour and commercially available baker's dried yeast, it could produce high qualities of breads using Hinohikari and Haenuki flours, when the amount of water added in dough was regulated. Particularly, it suggested that the amount of water added in dough might estimate from amylose contents of rice flours.

\section{References}

Aoki, N., Umemoto, T., \& Suzuki, Y. (2010). Properties of bread made using wheat gluten and rice flour from high-yielding cultivars. Nippon Shokuhin Kagaku Kogaku Kaishi, 57, 107-113. https://doi.org/ 10.3136/nskkk.57.107

Araki, E. (2010). Current state and study on rice flour use. Journal of Crop Research, 55, 59-64.

Arisaka, M., \& Yoshii, Y. (1991). Measurement of the starch damage of rice flour by acid solution process. Report of the Niigata Food Research Institute (Vol. 26, pp. 11-12).

Arisaka, M., Nakamura, K., \& Yoshii, Y. (1992). Properties of rice flour prepared by different milling methods. Denpun Kagaku, 39, 155-163. https://doi.org/10.5458/jag1972.39.155

Atwell, W. A. (2001). Wheat and flour testing: Wheat flour (pp. 27-65). St. Paul, MN: The American Association of Cereal Chemists. https://doi.org/10.1094/189112725X

Boye, J., Zare, F., \& Pletch, A. (2010). Pluse proteins: Processing characterization, functional properties and applications in food and feed. Food Research International, 43, 414-431. https://doi.org/10.1016/j.foodres. 2009.09.003

Chattopadhyay, S., Raychaudhuri, U., \& Chakraborty, R. (2013). Optimization of soy dessert on sensory, color, and rheological parameters using response surface methodology. Food Science and Biotechnology, 22, 47-54. https://doi.org/0.1007/s10068-013-0007-y

Japan Yeast Industry Association. (1996). Evaluation Methods for Bakers' Yeast. Tokyo.

Lin, L., Liu, H., Yu, Y., Lin, S., \& Mau, J. (2009). Quality and antioxidant property of buckwheat enhanced wheat bread. Food Chemistry, 37, 461-467. https://doi.org/10.1016/j.foodchem.2008.07.022

Ministry of Agriculture, Forestry and Fisheries (2017a). Food self-sufficiency rate in Japan. Retrieved from http://www.maff.go.jp/j/zyukyu/zikyu_ritu/012.html

Ministry of Agriculture, Forestry and Fisheries. (2017b). Statistics on food self-sufficiency rate. Retrieved from http://www.maff.go.jp/j/tokei/sihyo/data/02.html

Ministry of Internal Affairs and Communications. (2017). Family income and expenditure survey based on two or more person household by the Statistics Bureau. Retrieved from http://www.stat.go.jp/data/kakei/5.htm

Nagano, H., Okamoto, J., Kato, M., Nagashima, N., \& Omori, M. (2003). Experiment of Cookery Science by the Flow Chart (2nd ed., pp. 34-35). Tokyo: Chijinshokan.

Oda, Y., Yamauchi, H., \& Tamura, M. (2012). Development of baker's yeast “Tokachino" through Collaboration of Industry, Academia and Government. Nippon Shokuhin Kagaku Kogaku Kaishi, 59, 1-5. https://doi.org/ 10.3136/nskkk.59.1 
Ogawa, T., \& Nagai, K. (2011). Effects of milling methods on the quality of rice flours and breads made from rice flours. Bulletin of the Hyogo Prefectural Agricultural Institute, Agricultural Section, 59, 19-23.

Okunishi, T. (2015a). Future on rice flour bread. Journal of Cookery Science of Japan, 48, 385-391.

Okunishi, T. (2015b). Study on rice bread. Nippon Shokuhin Kagaku Kogaku Kaishi, 62, $303-306$. https://doi.org/10.3136/nskkk.62.303

Okunishi, T., Nakamura, K., Miyamoto, M., \& Miyashita, K. (2012). Determination of appropriate amount of water for making rice breads. Nippon Shokuhin Kagaku Kogaku Kaishi, 59, 409-413. https://doi.org/ 10.3136/nskkk.59.409

Rice Organization. (2017). Retrieved from http://www.komenet.jp/pdf/H27sakutuke.pdf\#search=027\%E6\% 97\%A5\%Е6\%9C\%AC\%E3\%81\%AE\%E7\%B1\%B3\%E3\%81\%AE\%Е7\%94\%9F\%E7\%94\%A3\%Е9\%87\% $8 \mathrm{~F}+\% \mathrm{E} 5 \% 93 \% 81 \% \mathrm{E} 7 \% \mathrm{~A} 8 \% \mathrm{AE} \% \mathrm{E} 5 \% 88 \% \mathrm{~A} 5 \% 27$

Sekiguchi, A. (2008). Studies on improvement of "Minowa" yeast. Reports of Gunma Industrial Technology Ceter (pp. 9-12).

Shimosaka, C. (2011). Preparation method and puffing behavior of bread with Shirakamikodama yeast. Journal of Cookery Science of Japan, 44, 223-230. https://doi.org/10.11402/cookeryscience.44.223

Shittu, T. A., Raji, A. O., \& Sanni, L. O. (2007). Bread from composite cassava-wheat flour: I. Effect of baking time and temperature on some physical properties of bread loaf. Food Research International, 40, $280-290$. https://doi.org/10.1016/j.foodres.2006.10.012

Shoji, N., Hanyu, Y., Mohri, S., Hatanaka, S., Ikeda, M., Togashi, C., \& Fujii, T. (2012). Evaluation of powder and hydration properties of rice flour milled by different techniques. Nippon Shokuhin Kagaku Kogaku Kaishi, 59, 192-198. https://doi.org/10.3136/nskkk.59.192

Sluimer, P. (2005). Principle in brief (Principles of breadmaking) (pp. 1-15). St. Paul: American Association of Cereal Chemists.

Takahashi, K., Okunishi, T., Suzuki, K., \& Yukizaki, C. (2011). Processing suitability evaluation method for rice bread and evaluation of rice flour produced in Miyazaki. Nippon Shokuhin Kagaku Kogaku Kaishi, 58, 55-61. https://doi.org/10.3136/nskkk.58.55

Takahashi, M., \& Yukizaki, C. (2011). Effects of gluten addition on specific volume of rice bread and trial manufacture of gluten-free rice bread. Report of Miyazaki Prefecture Industrial Technology Center \& Miyazaki Prefectural Food \& R\&D Center (Vol. 56, pp. 61-65).

Takahashi, M., Homma, N., Morohashi, K., Nakamura, K., \& Suzuki, Y. (2009). Effect of rice cultivar characteristics on the rice flour bread quality. Nippon Shokuhin Kagaku Kogaku Kaishi, 56, $394-402$. https://doi.org/10.3136/nskkk.56.394

Takano, H., Toyoshima, H., Koyanagi, Y., Watanabe, A., \& Tanaka, Y. (1986). Effect on rheological properties and bread making properties of composite rice-wheat flour in relation to the difference in particle size of the rice flour. Report of National Food Research Institute, 48, 43-51.

Tayama, K., Izumi, C., Fujikawa, M., Kanehiro, Y., Mabuchi, R., Okamoto, Y., .. Tanimoto, S. (2016). Isolation of yeast suitable for production of gluten-free rice flour bread and properties of the bread. Journal for the Integrated Study of Dietary Habits, 27, 22-30. https://doi.org/10.2740/jisdh.27.22

Tosa, N., Nozu, T., Akiyoshi, N., Oowatari, Y., Kamiike, T., Chikasige, K., \& Nagata, Y. (2015). Processing suitability of rice bread made from "Kinumusume" rice flour produced in Shimane and "Umehana" plum blossom yeast from the World Heritage Site Iwami-Ginzan. Nippon Shokuhin Kagaku Kogaku Kaishi, 62, 250-256. https://doi.org/10.3136/nskkk.62.250

Tronsmo, K., Faergestad, E., Schofield, J., \& Magnus, E. (2003). Wheat protein quality in relation to baking performance evaluated by the Chorleywood bread process and a hearth bread baking test. Journal of Cereal Science, 38, 205-215. https://doi.org/10.1016/S0733-5210(03)00027-4

Ulziijargal, E., Yang, J. H., Lin, L. Y., Chen, C. P., \& Mau, J. L. (2013). Quality of bread supplemented with mushroom mycelia. Food Chemistry, 138, 70-76. https://doi.org/10.1016/j.foodchem.2012.10.051

United States Department of Agriculture. (2017). Retrieved from http://usda.mannlib.cornell.edu/usda/current/ worldag-production/worldag-production-12-12-2017.pdf 
Yamazawa, M., Nakashima, C., Sakamoto, N., \& Hibino, K. (2012). Effect of rice flour milling methods on the quality of rice flour bread. Journal of Nagoya Bunri University, 12, 31-38.

Yoza, K., Okabe, M., \& Shima, J. (2008). Present state and issues of rice powder utilization: Rice bread. Nippon Shokuhin Kagaku Kogaku Kaishi, 55, 444-454. https://doi.org/10.3136/nskkk.55.444

\section{Copyrights}

Copyright for this article is retained by the author(s), with first publication rights granted to the journal.

This is an open-access article distributed under the terms and conditions of the Creative Commons Attribution license (http://creativecommons.org/licenses/by/4.0/). 